\title{
RED CROSS AND WELFARE SERVICE
}

In her paper on "Methods of analysing needs-Implementation of programmes and methodology", presented to the Health and Social Service Advisory Committee of the League of Red Cross Societies, at its Fifteenth Session in Geneva last October, Miss Marion Rothenbach, member of the ICRC, wrote that "National Societies have to cope with manifold needs which vary according to the sections of the community and between industrialized and developing countries". The developing countries are primarily concerned with vital needs: food, housing and a minimum income. Countries which have already attained a certain standard of living are mostly concerned with problems at a different level, such as education. At a third level, another set of problems connected with the quality of life have to be dealt with. National Societies have therefore to regard problems in the spheres of health and social welfare at those three levels.

"In our view", said Miss Rothenbach, "National Societies have the main task of examining all problems in the spheres of health and social welfare and providing the 'tools' such as material, technical, human and financial resources, or the guidelines in a specific field through information or training seminars, etc." The idea behind this approach comes closer to the concept of what, in social welfare, is today called community work, through which the members of the community become involved in the general programme of development. As may be seen, community work includes practically all the activities carried out by the Red Cross: cultural, recreational, educational, economic, vocational or prevocational programmes; plans for the promotion of health and the protection of the environment, and so forth. The League therefore considered that it would be useful to continue the work already 
begun with the publication of two guides ${ }^{1}$ by issuing a third booklet entitled Guide on Community Red Cross Work. The League's Social Welfare Unit introduces this publication in its foreword:

"While these two guides were, on the whole, geared towards the individual approach in the welfare field, it was felt that, at a time when the field of social work is putting its emphasis on a global approach to the problems of communities, and when social welfare efforts are being geared towards social development as an essential part of a total development, the Red Cross World should be aware of and involved in this trend.

From its beginning, the Red Cross has been involved, one way or another, in community work and as such, has gradually extended its activities from emergency measures in case of accidents or disasters to long-term medical and welfare services which, however, have too often been programmed on intuition or carried over from the past without consulting the beneficiaries.

Over the past years there has been a growing awareness both within and outside the Red Cross of the necessity to call on the participation of the people concerned and make them responsible for their own future and the improvement of the quality of life.

Consequently, the present publication has been prepared in order to assist National Societies wishing to develop their work in the community in a more systematic way, and thus participate in its social development, to recognize the needs of their community, and help the people concerned to help themselves.

This guide, which deals with :

- What is community work?

-Who does community work?

- How to prepare those working in the community

will require adaptation to the particular situation in each country, taking into account needs and availables resources, be it at national, regional or local level."

\footnotetext{
${ }^{1}$ Guide for a Red Cross Welfare Service (1965) and Guide for the Preparation of the Red Cross Welfare Leader (1969).
} 